\title{
Assembly rules for ground beetle communities: What determines community structure, environmental factors or competition?
}

\author{
Sonomi SHIBUYA ${ }^{1}$, Kohei KUBOTA², Masahiko OHSAWA³ and ZAAL KIKVIDZE ${ }^{1}$ \\ ${ }^{1}$ Laboratory of Biosphere Functions, Department of Natural Environmental Studies, Graduate School of Frontier Sciences, \\ The University of Tokyo, Kashiwanoha 5-1-5, Kashiwa, Chiba 277-8563, Japan; e-mail: sshibuya@nenv.k.u-tokyo.ac.jp \\ ${ }^{2}$ Laboratory of Forest Zoology, Graduate School of Agricultural and Life Sciences, The University of Tokyo, Yayoi, Bunkyo-ku, \\ Tokyo 113-8657, Japan \\ ${ }^{3}$ Institute of Biological Sciences, Faculty of Science, The University of Malaya, Kuala Lumpur 50603, Malaysia
}

Key words. Carabidae, ground beetles, community structure, assembly rules, environmental factors

\begin{abstract}
Species assembly in ground beetle (Coleoptera: Carabidae) communities in local microhabitats was studied in a forest. The following questions were addressed: are there important filters that sort the species in the assemblages? If so, what is the specific nature of these filters? In order to address these questions rarefaction analysis was used to determine whether ground beetle species are distributed non-randomly. Next, the nature of filters was determined by analyzing (1) the community matrix and searching for the consequences of competitive exclusion and (2) species-environmental relations. Rarefaction analysis revealed that the species composition is filtered: species richness was less than expected and there were fewer than expected congeneric species coexisting at high beetle population densities. However, community matrix and body size analyses did not detect significant competition among the beetle species and the matrix was significantly nested. Species-environmental analyses indicated that the ground beetle assembly was strongly linked to ground vegetation. It is concluded that spatial distribution of ground beetles across local communities in this forest habitat is determined more by local environmental conditions than competition, and ground beetles do not interact strongly among themselves so that competitive effects do not play an important role in their distribution except at high beetle population densities.
\end{abstract}

\section{INTRODUCTION}

Community assembly is usually attributed to "filters" that sieve species from the regional pool and thus generate non-random distributions of species across local communities. It basically consists of two types of consecutive filtering processes (Lortie et al., 2004): (1) which sort those species that can persist within a community by their fitness or preference for particular local abiotic conditions, and (2) biotic interactions such as competitive exclusion. The first filter determines the sub-set of species that can potentially thrive in a particular local environment based on their adaptation and life history. The second filter may further reduce the number of coexisting species by competition among species with overlapping niches resulting in the exclusion of some of the species.

In general, ground beetles show a clear association with environmental factors such as temperature, moisture and light (Thiele, 1977), forest floor vegetation cover (Niemelä \& Spence, 1994; Migliorini et al., 2002; Mazía et al., 2006), canopy tree cover (Niemelä \& Spence, 1994; Niemelä et al., 1996; Koivula et al., 2002), litter cover (Magura, 2002; Poole et al., 2003) and diversity of vegetation (Halme \& Niemelä, 1993; Jukes et al., 2001). Ground beetles are increasingly being studied because they are very sensitive to environmental changes (Thiele, 1977; Niemelä et al., 2000; Scott \& Anderson, 2003) and thus potentially excellent bio-indicators (Butterfield et al., 1995; Rainio \& Niemelä, 2003; Pearce \& Venier, 2006).
On the role of competition, however, opinions differ (Niemelä, 1993): although some researchers favour the idea that competition is not common among ground beetles (e.g., Thiele, 1977; Loreau, 1990) other studies suggest it is important in shaping community structure (e.g. Huk, 2009). Competition is important in laboratory studies (e.g., Currie et al., 1996). There are studies of the role of competition in speciation but for a few species in nature (Sota et al., 2000; Okuzaki et al., 2010). There are few if any studies on the role of competition in structuring ground beetle communities along environmental gradients, even though such studies are crucial for the understanding the assembly of beetle communities.

Here the assembly of ground beetle communities (Coleoptera: Carabidae) across microhabitats within a forest habitat is studied. First the filtering species composition at the community level was detected using a rarefaction model. This model produces an expected species accumulation curve assuming no filters and comparison of the expected and observed curves can reveal whether local conditions sort species (Gotelli \& Colwell, 2001). There are some good examples of the use of rarefaction curves in analyses of biodiversity patterns of Carabidae assemblages (Gunnarsson et al., 2004; Sackmann et al., 2006; Niemelä \& Kotze, 2009; Melis et al., 2010).

The second step was devoted to analyzing the two types of filtering processes (above) and involved two kinds of investigation. One focused on competition among beetles. Whether competition is important ultimately must be 
determined experimentally, although density-dependent patterns may also indicate competition. Indeed, since more similar species must compete with each other more strongly than less similar ones, it is expected that genusto-species ratios will reflect this and be detected by using a random null-model similar to rarefaction analysis (Gotelli \& Graves, 1996, p. 27). The consequences of interspecific competition versus other community processes were also looked for by analyzing co-occurrence of species and nestedness of the community matrix. For intra-specific competition, the dependence of body size of individual beetles on their density was examined; theory predicts that at high densities the organisms compete more intensively and thus affect each other's growth. Another kind of investigation focused on local environmental conditions. Nine environmental variables were recorded and a canonical correspondence analysis (CCA) used to identify the environmental factors controlling the distribution of ground beetle species along ecological gradients. The species' optima were analyzed along the important environmental gradients that were selected using CCA.

\section{MATERIAL AND METHODS}

\section{Study site}

This study was carried out in secondary forest (Musashi Hill Woodland National Park, Saitama Prefecture, central Japan, 304 ha, $36^{\circ} 04^{\prime} \mathrm{N}, 139^{\circ} 22^{\prime} \mathrm{E}, 40$ to $90 \mathrm{~m}$ a.s.l., see Yokohari \& Kurita, 2003 for more details). The study site is located in a humid warm-temperate part of Japan with a maximum summer temperature of $33^{\circ} \mathrm{C}$ in August, minimum winter temperature of $-3^{\circ} \mathrm{C}$ in January and mean annual temperature of $14.8^{\circ} \mathrm{C}$; annual precipitation averages $1479 \mathrm{~mm}$ (meteorological data measured in the park during 2004-2006). Although forest floor vegetation is cleared and litter removed, tree felling rarely occurred after the park was established in 1974. The forest is dominated by deciduous oak Quercus serrata mixed with the evergreen conifer Pinus densiflora.

Twenty sampling plots were set randomly within an area of 50 ha in the secondary forest. Plot size was $10 \mathrm{~m} \times 10 \mathrm{~m}$, and the 20 plots were used for sampling ground beetles and recording environmental variables.

\section{Ground beetle sampling}

Pitfall traps without bait (plastic cups: $6.5 \mathrm{~cm}$ top diameter by $7.5 \mathrm{~cm}$ deep with five tiny holes for drainage) were used to sample the ground beetles. Twenty traps were set $2 \mathrm{~m}$ apart in a grid pattern within each plot. Traps were installed and left in place for five consecutive days, after which all trapped animals were collected. This sampling procedure was conducted once per month from May to July and from September to November 2006 (overall 20 traps $\times 20$ plots $\times 6$ times). All collected animals were brought back to the laboratory, identified and counted. The adults of the ground beetles (Coleoptera: Carabidae) were analyzed. The abundance of each species was the number of individuals caught. All species for which $\geq 5$ individuals were caught were included in the CCA.

\section{Description of environmental variables}

Nine environmental variables were measured: tree diversity, tree basal area, diversity of forest floor vegetation, abundance of forest floor vegetation, litter weight, fermentation/humus weight, soil water content, soil surface temperature and expo- sure to the sky (openness), which are thought to influence beetle assemblages (see Introduction).

For the description of the tree canopy, the species of all individuals within 20 plots were identified and the diameter at breast height $(\mathrm{DBH})$ of individuals taller than $1.3 \mathrm{~m}$ was measured in June 2006. For each species, the basal area was calculated from the DBH data and used as a measure of tree abundance to calculate Simpson's index of diversity:

$$
\text { Simspon's diversity }=1 / \Sigma p_{i}^{2},
$$

where $p_{i}$ is the proportion of the total abundance accounted for by the $i$ th species (Magurran, 2004).

For the forest floor vegetation, all herbaceous plants and trees shorter than $1.3 \mathrm{~m}$ were identified in June 2006. The height and cover (\%) of each species within 20 plots were recorded and monitored once a month from May to July and from September to November 2006. The abundance of a given species was calculated by multiplying its total coverage by its mean height. This measure of abundance was used to calculate Simpson's diversity index in the same way as for trees (above).

Samples of litter and the fermentation/humus layer were collected from four small quadrats $(0.3 \mathrm{~m} \times 0.3 \mathrm{~m})$ within each plot in May and December 2006. The samples were oven-dried at $80^{\circ} \mathrm{C}$ for $48 \mathrm{~h}$ and then weighed to calculate mean values for each plot.

Soil water content (volume \%) was measured at four points within each plot using a Hydrosense CS 620 soil moisture measurement system (Campbell Scientific Inc., Logan, UT) with $20-\mathrm{cm}$ probe rods. A SK-25WP soil temperature-measuring instrument (Sato Instruments Corporation, Tokyo, Japan) was used to record the surface soil temperature (at a depth of 0.5 $\mathrm{cm}$ ). Soil measurements were taken once a month from May to July and from September to November 2006.

For measuring exposure to the sky, hemispherical photographs were taken $50 \mathrm{~cm}$ above the ground at four points within each plot in September 2006; mean exposure (\%) was calculated using software CanopOn 2.02 (http://takenaka-akio.cool.ne.jp/ etc/canopon2/).

Software Statistix 9 (Analytical Software, Tallahassee, FL, U.S.A) was used for the descriptive statistics of environmental variables.

\section{Data analyses}

Filtering species composition

A rarefaction null-model was used to detect filtering beetle species composition across plots. Rarefaction curves are created by randomly re-sampling the pool of samples many times. Rarefaction generates expected values for species richness in a small collection of a certain number of individuals drawn at random from a large species pool (combined samples). The species pool was constructed by combining all the beetles caught in all the plots and summing the numbers of individuals across the plots. The resultant totals were used as a measure of the abundance of each species. The resultant species pool was used in the rarefaction analysis (software Ecosim available at http:// garyentsminger.com/ecosim.htm, Gotelli \& Entsminger, 2010). The process of random drawing was repeated 1000 times to generate a mean and a variance of species diversity. EcoSim calculates the mean species richness for a given abundance class used to construct the expected species accumulation curves and $95 \%$ CIs. The dependence of the difference between the expected and observed richness on the density of beetles was determined using regression analysis (software Statistix 9, above) 
TABLE 1. Abundance distribution and density of ground beetle species in the different plots.

\begin{tabular}{|c|c|c|c|c|c|c|c|c|c|c|c|c|c|c|c|c|c|c|c|c|c|}
\hline Species & & & & & & & & & & $\mathrm{Plc}$ & & & & & & & & & & & Total \\
\hline Pterostichus yoritomus & 44 & 79 & 51 & 35 & 75 & 25 & 17 & 13 & 11 & 23 & 45 & 84 & 12 & 38 & 35 & 21 & 96 & 27 & 23 & 18 & 772 \\
\hline Carabus insulicola & 40 & 38 & 58 & 29 & 37 & 13 & 22 & 18 & 31 & 38 & 24 & 11 & 15 & 17 & 15 & 3 & 12 & 13 & 9 & 25 & 468 \\
\hline Lesticus magnus & 2 & 14 & 19 & 13 & 17 & 1 & 2 & 4 & 2 & 5 & 13 & 31 & 16 & 10 & 6 & 5 & 5 & 9 & 14 & 15 & 203 \\
\hline Chlaenius naeviger & 4 & 16 & 5 & 1 & 21 & 5 & 0 & 2 & 3 & 4 & 11 & 2 & 2 & 21 & 0 & 15 & 3 & 3 & 10 & 6 & 134 \\
\hline Synuchus cycloderus & 2 & 2 & 1 & 0 & 4 & 13 & 10 & 10 & 5 & 2 & 10 & 8 & 4 & 10 & 4 & 5 & 8 & 0 & 21 & 11 & 130 \\
\hline Pterostichus microcephalus & 0 & 0 & 0 & 0 & 0 & 2 & 0 & 2 & 1 & 0 & 36 & 34 & 9 & 2 & 1 & 0 & 0 & 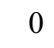 & 1 & 0 & 88 \\
\hline Synuchus nitidus & 1 & 7 & 0 & 0 & 0 & 0 & 10 & 2 & 5 & 0 & 0 & 0 & 1 & 2 & 1 & 0 & 1 & 1 & 1 & 4 & 36 \\
\hline Haplochlaenius c & 1 & 1 & 1 & 4 & 5 & 0 & 3 & 4 & 1 & 1 & 4 & 3 & 2 & 1 & 0 & 0 & 0 & 0 & 1 & 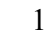 & 33 \\
\hline Pterostichus poly & 0 & 0 & 1 & 0 & 1 & 1 & 1 & 0 & 0 & 0 & 1 & 1 & 2 & 4 & 0 & 2 & 4 & 1 & 1 & 0 & 20 \\
\hline Leptocarabu & 1 & 2 & 0 & 0 & 1 & 0 & 1 & 0 & 0 & 2 & 0 & 0 & 0 & 0 & 2 & 4 & 2 & . & 2 & 0 & 17 \\
\hline Harpalus dis & 0 & 0 & 0 & 1 & 0 & 0 & 0 & 7 & 1 & 1 & 0 & 2 & 0 & 0 & 0 & 0 & 1 & 0 & 0 & 4 & 17 \\
\hline Myas & 0 & 0 & 2 & 0 & 0 & 0 & 2 & 1 & 1 & 2 & 0 & 0 & 1 & 0 & 1 & 1 & 1 & 2 & 0 & 2 & 16 \\
\hline Sупис & 0 & 0 & 1 & 0 & 0 & 0 & 0 & 1 & 1 & 0 & 2 & 0 & 2 & 0 & 1 & 2 & 0 & 3 & ? & 1 & 16 \\
\hline Diploche & 0 & 0 & 0 & 0 & 0 & 0 & 0 & 0 & 0 & 0 & 0 & 1 & 3 & 0 & 0 & 0 & 1 & 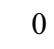 & 0 & & 14 \\
\hline Trigonot & 1 & 0 & 1 & 2 & 1 & 0 & 0 & 0 & 0 & 0 & 0 & 0 & 0 & 0 & 0 & 1 & 0 & 0 & 0 & 0 & 6 \\
\hline Synuchus ar & 0 & 0 & 0 & 0 & 0 & 0 & 3 & 1 & 0 & 0 & 0 & 0 & 0 & 0 & 0 & 1 & 0 & 0 & 0 & 0 & 5 \\
\hline Brachinus sc & 0 & 0 & 0 & 0 & 0 & 0 & 0 & 1 & 0 & 0 & 1 & 0 & 0 & 0 & 0 & 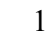 & 1 & . & 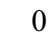 & 0 & 4 \\
\hline Chlaenius $v$ & 1 & 0 & 0 & 0 & 0 & 0 & 0 & 0 & 0 & 0 & 2 & 0 & 0 & 0 & 0 & 0 & 0 & 0 & 0 & 0 & 3 \\
\hline Hemicarabus & 0 & 0 & 0 & 0 & 0 & 0 & 1 & 0 & 0 & 0 & 1 & 0 & 0 & 0 & 0 & 0 & 0 & 0 & 0 & 0 & 2 \\
\hline Amara $m$ & 0 & 0 & 0 & 0 & 0 & 0 & 0 & 0 & 0 & 0 & 1 & 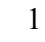 & 0 & 0 & 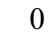 & 0 & 0 & 0 & 0 & 0 & \\
\hline Anisodactylus $t$ & 0 & 0 & 0 & 1 & 0 & 0 & 0 & 0 & 0 & 0 & 0 & 0 & 0 & 1 & 0 & 0 & 0 & 0 & 0 & 0 & \\
\hline Chlaenius $m$ & 0 & 0 & 0 & 0 & 0 & 0 & 0 & 0 & 0 & 0 & 1 & 0 & 1 & 0 & 0 & 0 & 0 & 0 & 0 & 0 & 2 \\
\hline Damaster blaptoides & 0 & 0 & 0 & 0 & 1 & 0 & 0 & 0 & 0 & 0 & 0 & 0 & 0 & 0 & 0 & 0 & 0 & 0 & 0 & 0 & 1 \\
\hline Pteros & 0 & 0 & 0 & 0 & 0 & 0 & 0 & 0 & 0 & 0 & 0 & 0 & 0 & 0 & 1 & 0 & 0 & 0 & 0 & 0 & 1 \\
\hline Dolichus halensis & 0 & 0 & 0 & 0 & 0 & 0 & 0 & 0 & 0 & 0 & 0 & 0 & 0 & 1 & 0 & 0 & 0 & 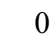 & 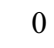 & 0 & 1 \\
\hline Anisodactylus sadoensis & 0 & 0 & 0 & 0 & 0 & 0 & 0 & 0 & 0 & 0 & 1 & 0 & 0 & 0 & 0 & 0 & 0 & 0 & $\sigma$ & 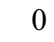 & 1 \\
\hline Harpalus tridens & 0 & 0 & 0 & 0 & 0 & 0 & 0 & 0 & 0 & 1 & 0 & 0 & 0 & 0 & 0 & 0 & P & 0 & 0 & 0 & 1 \\
\hline Harpalus crates & 0 & 0 & 0 & 0 & 0 & 0 & 0 & 0 & 0 & 0 & 1 & 0 & 0 & 0 & 0 & 0 & 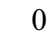 & 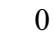 & 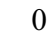 & 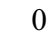 & 1 \\
\hline Oxycentrus argut & 0 & 0 & 0 & 1 & 0 & 0 & 0 & 0 & 0 & 0 & 0 & 0 & 8 & 0 & 0 & 0 & 0 & 0 & 0 & 0 & 1 \\
\hline Anoplogenius cyanescens & 0 & 0 & 0 & 0 & 0 & 0 & 0 & 0 & 0 & 0 & 0 & 0 & 0 & 0 & 1 & 0 & 0 & 0 & 0 & 0 & 1 \\
\hline otal & 7 & $\gamma_{0}$ & 40 & 87 & 3 & 60 & 2 & 66 & 62 & 79 & 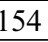 & 8 & 10 & 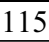 & 68 & 61 & 35 & 59 & 85 & 88 & \\
\hline
\end{tabular}

\section{Beetle interactions}

A rarefaction analysis was used to detect whether congeneric Carabidae species coexisted in the same habitat less often than expected (above, see also Gotelli \& Graves, 1996). Genus-tospecies ratios were calculated for each of the 1000 randomizations and the mean value was the expected number. The dependence of the difference between the expected and observed values of the genus-to-species ratio on density was determined using regression analysis (software Statistix 9, above).

The pattern of the species distribution in the beetle community matrix was used to detect the consequences of interspecific competition. One such consequence is negative co-occurrence: species coincide in the local assemblages less frequently than expected from the random null-model due to competitive exclusion. Co-occurrence was assessed with $\mathrm{C}$-scores using software Ecosim (above). In a competitively structured community, the $\mathrm{C}$-score should be significantly larger than expected by chance. Another index, the variance ratio (V-ratio), measures the covariance of species across local assemblages. If the species are distributed independently the expected V-ratio is 1.0. If there is strong negative covariance between species pairs across plots due to competitive exclusion, the variance ratio will be $<1.0$. However, other processes may be more important than competitive exclusion in shaping the community matrix. One such process is indicated by nestedness. In a nested matrix species found in small assemblages are found also in larger assemblages - species do not turn over local assemblages but simply drop out in a certain order (e.g., as a result of differences in dispersal ability). Nestedness is indicated by "matrix temperature": the "colder" the system, the more fixed the order in which the species drop out. The software BINMATNEST was used to measure nestedness in terms of matrix temperature (available at http://www.eeza.csic.es/personales/rgirones.aspx, RodríguezGironés \& Santamaria, 2006).

To detect intra-specific competition, the relationship between beetle density (number of individuals per plot) and body size (mean body length per plot) was determined using regression analysis (software Statistix 9, above). Body size (from the front margin of the labrum to the apical part of elytra) of the three most abundant species (772 individuals of Pterostichus yoritomus, 468 of Carabus insulicola and 203 of Lesticus magunus) was measured.

\section{Species-environmental relations}

The relationships between environmental variables and species occurrence were tested using Canonical correspondence analysis (CCA). The numbers of individuals of the different species of beetle in the main matrix was logarithmically $\left(\log _{10} \mathrm{x}+\right.$ 1) transformed to reduce the great differences in abundance between species. The nine environmental variables were used in the second matrix. CCA was carried out using software CANOCO 4.5 (ter Braak \& Šmilauer, 2002) and the significance of the CCA axes and environmental variables was determined by Monte Carlo tests (999 randomizations). Co-linearity among environmental variables was tested with the Variance Inflation Factor (VIF, Statistix 9, above) to check whether these variables are redundant. 


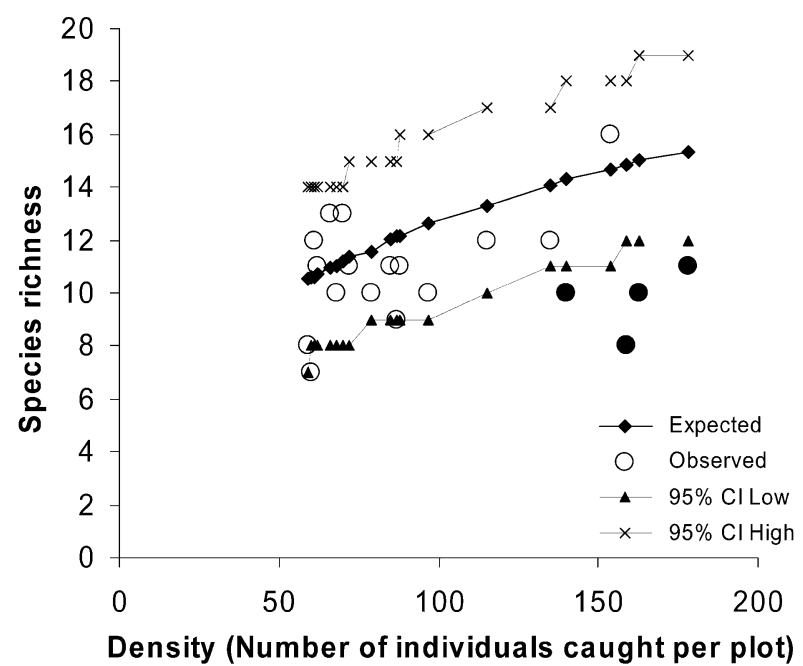

Fig. 1. Rarefaction curve, with confidence intervals, of the expected values of species richness relative to the population density (abundance, number of individuals per plot) of beetles. Circles (O) are observed richness for 20 plots and the solid circles indicate the four plots that lie outside of the $95 \%$ CIs.
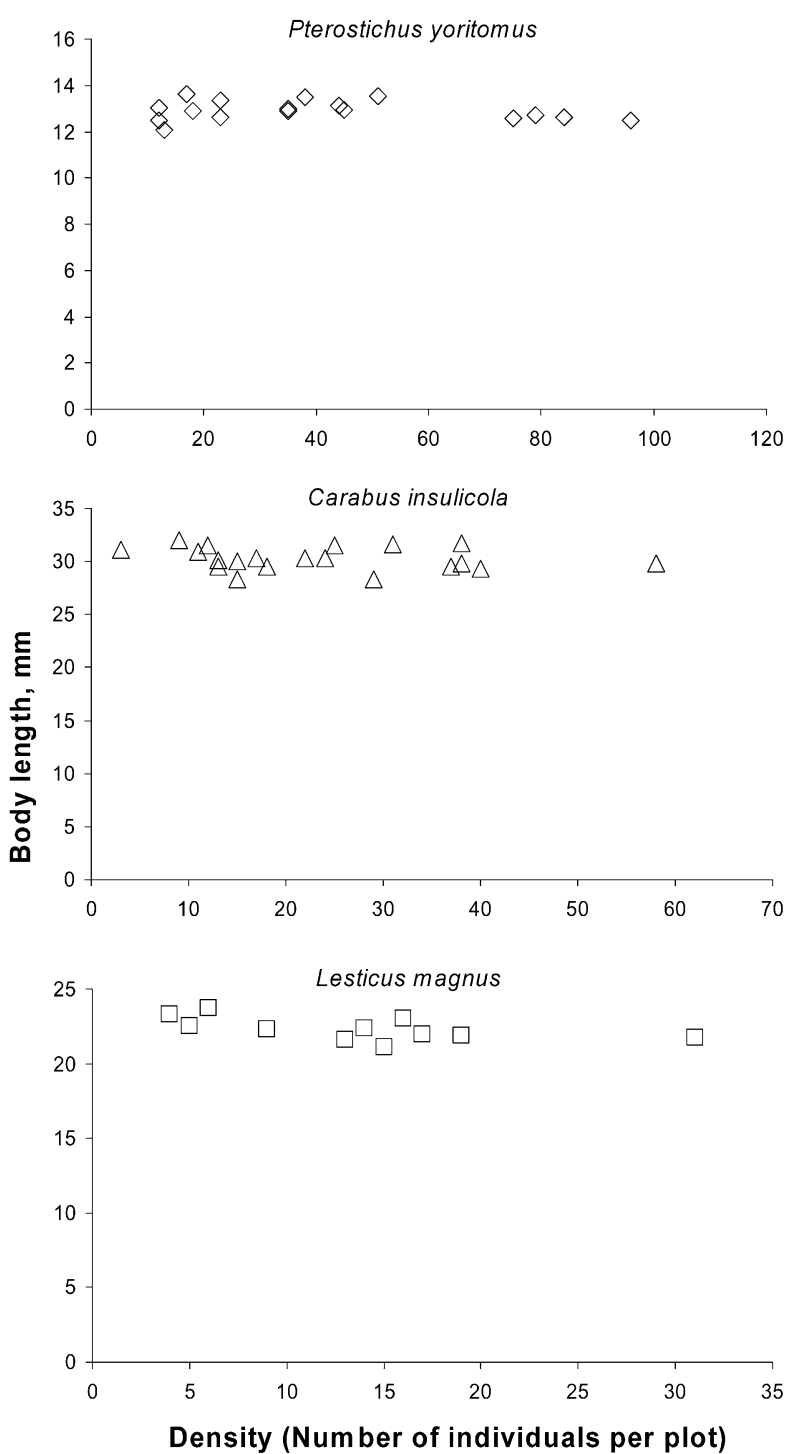

Fig. 2. Relationships between body length and population density for the three most abundant beetle species.

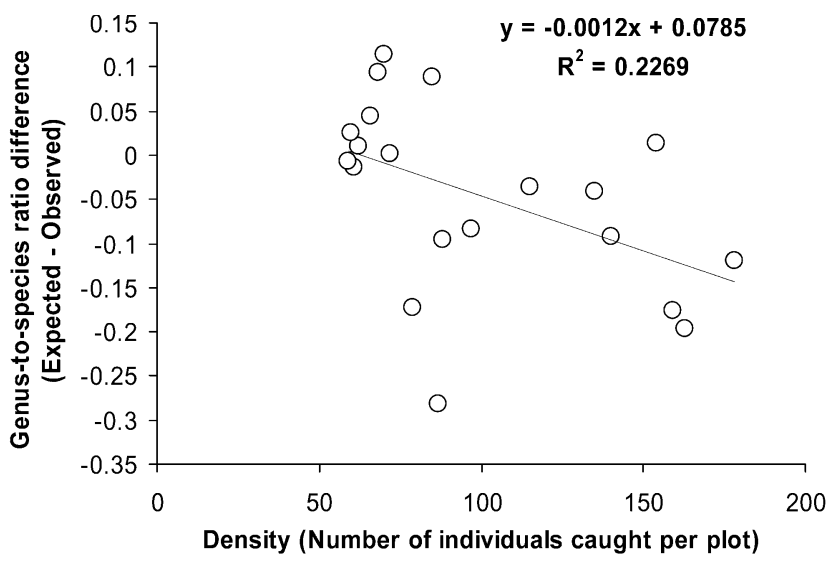

Fig. 3. Relationship between the difference between the expected and observed values of the genus-to-species ratio and the population density of beetles.

The species optima for different environmental factors were determined by picking the plot with a maximum number of individuals for a given beetle species and using the corresponding values of environmental variables. If there were more than one plot with the same number of beetle individuals, mean values for the environmental variables were used.

\section{RESULTS}

Thirty species of ground beetles were identified among the 1998 individuals caught by pit-fall traps (Table 1). The expected values species accumulation curve of the species richness in plots at corresponding densities (number of individuals per plot) constructed using the rarefaction null-model reveals that four out of the 20 plots lie outside the 95\% CI (Fig. 1), and these four outliers (solid circles) were mostly for plots with the highest beetle densities. As a result of the regression analysis of the difference between the expected and observed species richness increased with increasing density of beetles per plot, with a slope of $0.0344(p=0.0081)$.

The difference between the expected and observed values of genus-to-species ratio decreased significantly with increasing beetle density $(p=0.0338$; Fig. 3$)$. Community matrix analyses did not detect negative co-

TABLE 2. Descriptive statistics of the environmental variables measured in the 20 plots at the study site.

\begin{tabular}{lc}
\hline Environmental variable & Mean $\pm \mathrm{SD}$ \\
\hline \multicolumn{1}{c}{ Biotic factors } \\
\hline $\begin{array}{l}\text { Tree diversity }(\mathrm{Simpson} \text { 's index) } \\
\text { Tree basal area }\left(\mathrm{m}^{2} / \mathrm{ha}\right)\end{array}$ & $2.19 \pm 0.90$ \\
$\begin{array}{l}\text { Diversity of forest floor vegetation } \\
\text { (Simpson's index) }\end{array}$ & $30.43 \pm 13.18$ \\
$\begin{array}{l}\text { Abundance of forest floor vegetation } \\
(\text { cover } \% \times \text { mean height) }\end{array}$ & $4.12 \pm 4.02$ \\
Litter dry weight $\left(\mathrm{kg} / 100 \mathrm{~m}^{2}\right)$ & $17.26 \pm 18.31$ \\
Fermentation / Humus dry weight $\left(\mathrm{kg} / 100 \mathrm{~m}^{2}\right)$ & $20.21 \pm 6.02$ \\
\hline \multicolumn{2}{c}{ Abiotic factors } \\
\hline $\begin{array}{l}\text { Soil water content at } 20 \mathrm{~cm} \text { depth }(\%) \\
\text { Soil surface temperature }\left({ }^{\circ} \mathrm{C}\right)\end{array}$ \\
Exposure to the sky $(\%)$
\end{tabular}




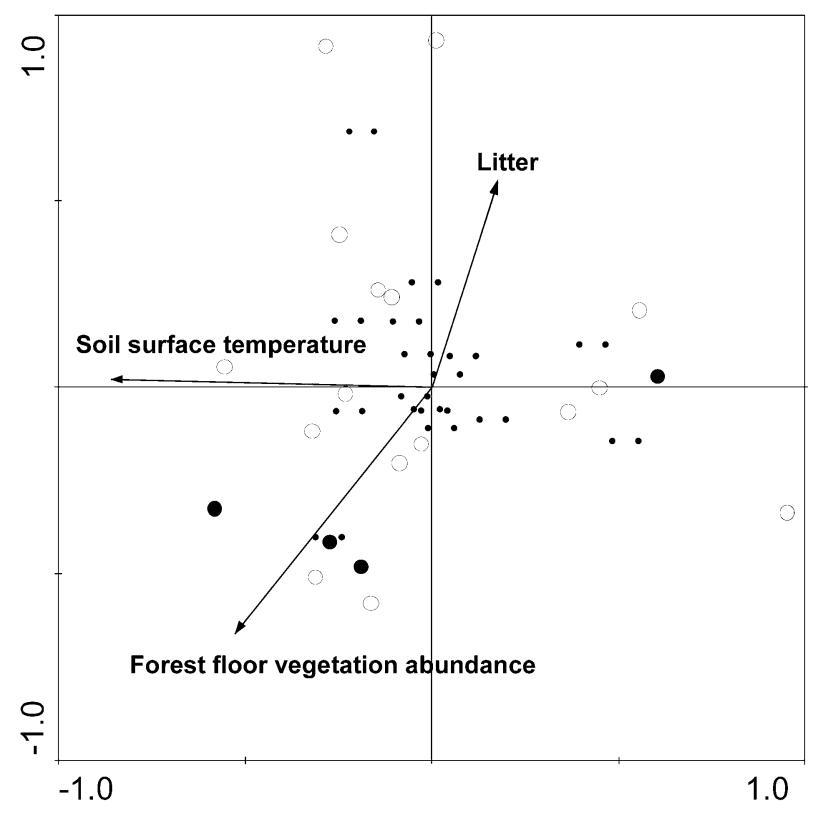

Fig. 4. CCA ordination of the ground beetle community: the species-environmental variables (dots) and the plotenvironmental variables (circles). Solid circles indicate the position of the four outlying plots (Fig. 1).

occurrence of species across plots since the observed C-score (5.89) was indistinguishable from the expected value predicted by the random null-model $(5.825, \mathrm{p}=$ $0.575)$. The observed V-ratio (1.028) was also very close to the expected value $(1.00, \mathrm{p}=0.5958)$ indicating insignificant covariance of species across plots. In turn, the nestedness analysis detected a significantly cool matrix temperature (26.81, p $<0.0005)$, which indicates a strongly nested distribution of beetle species across plots. The dependence of body size on beetle density for the three most abundant species (Fig. 2) used to detect intraspecific competition, did not vary considerably and did not depend on beetle density.

The analysis of the nine environmental variables recorded in plots and described in terms of SD values, indicates a certain degree of microhabitat heterogeneity (Table 2). CCA ordinated the ground beetle community along both the species-environmental variables (Fig. 4, dots) and the plot-environmental variables (Fig. 4, circles). CCA was overall significant ( $\mathrm{P}=0.01$ using the Test of significance of all canonical axes). Cumulatively, first and second axes of the CCA explained $61.2 \%$ of the variance in the species-environment relations (Eigenvalues equaled to 0.109 and 0.085 for the CCA Axis 1 and Axis 2, respectively). Among the environmental variables, three appeared significant for ordination: soil surface temperature $(\mathrm{p}=0.001)$, abundance of forest floor vegetation $(\mathrm{P}=0.002)$ and litter dry weight $(\mathrm{P}=0.042)$. Judging from the length of the arrows, soil surface temperature and abundance of forest floor vegetation were of great importance in explaining variation within the data than litter (Fig. 4). Variance inflation factor calculated for these three variables did not detect significant co-linearity (VIF < 1.5). As mentioned above, rarefaction analysis

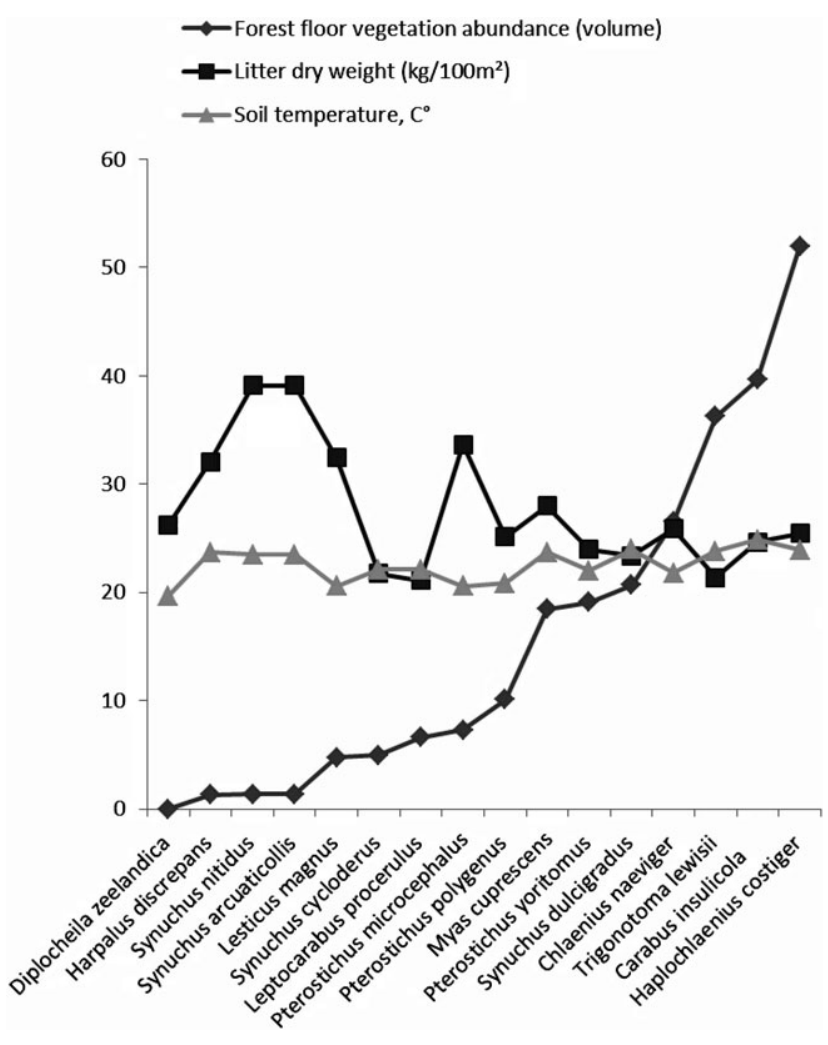

Fig. 5. Ranking of beetle optima by forest floor vegetation abundance and corresponding values of soil temperature and quantity of litter. Species found where there is little forest floor vegetation are recorded from plots where there are large quantities of litter.

indicated four plots as outliers with significantly lower observed richness compared to the expected number of species in these plots (solid circles, see Fig. 1). Three out of these four plots (solid circles, Fig. 4) tended to occur at high abundances of forest floor vegetation. The ranking of beetle species according to their optima along forest floor vegetation abundance, litter mass and soil surface temperature showed that species with optima at low forest floor vegetation were associated with high litter plots (Fig. 5), which may explain the rather opposite direction of corresponding arrows on the CCA biplot (Fig. 4).

\section{DISCUSSION}

A rarefaction model was used to detect how species richness depended on ground beetle density. If the observed species richness values do not differ from that expected, then no species-specific filters can be inferred (Gotelli \& Colwell, 2001). The results presented indicate that the difference between the expected richness predicted by the random-null model and that observed increased with increasing density of beetles, which indicates that species composition is filtered. Such an analysis does not take into account the specific nature of these filters and indicates only their collective effect. However, since competition is a density-dependent process, the lower than expected richness, especially at higher beetle densities (high abundance per plot), might imply that species were competitively excluded. Further indication of 
competitive exclusion is provided by the difference between the expected and observed genus-to-species ratios that decreased with increasing beetle density, thus indicating lower than expected occurrence of congeneric species at high densities of beetles. In other words, taxonomic similarity of co-occurring species declined with increasing density. If taxonomic and ecological similarities are more or less related, then the above results could indicate the consequences of on-going competitive exclusion among taxonomically (and therefore ecologically) similar species at least at high beetle densities.

How important is competitive exclusion in the overall filtering of species composition? The other analyses do not indicate competition as an important process. First, the analyses of the community matrix did not detect patterns that could be interpreted as consequences of interspecific competition. In addition, the community matrix was nested. In general, nestedness is interpreted as a result of differences in the dispersal abilities of the member species, or differences in their local extinction rates, or the combination of these two (e.g., RodríguezGironés \& Santamaría, 2006). The current level of knowledge, however, only allows one to speculate about the mechanisms generating the nested pattern of the community matrix. In addition, body size did not depend on the density of beetles, indicating that intra-specific competition is unimportant. Beetles can reduce competition for food by moving elsewhere, since ground-dwelling beetles are not restricted by space. Probably, competitive effects are important only when beetles are abundant or resources limited (Gotelli \& Craves, 1996, p. 9) and have an additive effect on the filtering by local environmental conditions (Lortie et al., 2004). Indeed, due to effective niche segregation among beetle species and their low density in nature, competition may not strongly affect the structure of ground beetle community matrices.

How important are the local environmental conditions in filtering species composition? CCA indicated that the abundance of forest floor vegetation, soil surface temperature and, to a less extent, the amount of litter, is associated with the distribution of beetle species. As ground beetles dwell in the topsoil, soil surface conditions are important for beetles. Indeed, beetles are especially sensitive to temperature, which directly affects ground beetle activity (Thiele, 1977). Habitat structure, in particular, plant cover and litter, is important for ground-dwelling arthropods (Gardner et al., 1995) and ground beetles in particular (Ings \& Hartley, 1999; Antvogel \& Bonn, 2001). Plants and litter can be an important determinant of the abundance of herbivore invertebrate prey of beetles. Comparison of species optima along the environmental variables indicates that beetles species appear to differ in their preferences for ground vegetation abundance versus quantity of litter, so that a large quantity of litter could compensate for the lack of forest floor vegetation. Thus, ground vegetation and litter may determine beetle composition by providing a food resource through the food chain: plants $\rightarrow$ herbivorous insects $\rightarrow$ polyphagous predators. In addition, ground beetles are very sensi- tive to microclimatic conditions (Thiele, 1977; Antvogel \& Bonn, 2001; Mullen et al., 2008), which may explain the dependence of beetle species composition on vegetation, since forest floor vegetation can strongly modify microclimate. Probably, alterations in soil surface temperature caused primarily by forest floor vegetation could affect the local assembly of ground beetles recorded in this study. Overall, vegetation cover may be an integrative measure of microclimatic conditions and the ground beetle assembly may depend on local microclimate.

It is concluded that the spatial distribution of ground beetles across microhabitats in this forest depends primarily on filtering by local environmental conditions rather than competition, and ground beetles do not interact strongly among themselves so that competitive effects do not play an important role in their distributions except at high population densities. This interpretation is based on the fact that ground beetles are mobile organisms and can avoid competition, so that pre-emption of resources should not have a considerable effect on the coexistence of ground beetles. Overall, the use of the rarefaction technique in this study revealed species sorting across local assemblages in a forest habitat, but understanding the mechanisms shaping community structure requires additional analyses.

ACKNOWLEDGEMENTS. We thank T. Tajima and A. Inoue for assistance with the fieldwork and the administration of the Musashi-Kyûryô National Park for their co-operation.

\section{REFERENCES}

Antvogel H. \& Bonn A. 2001: Environmental parameters and microspatial distribution of insects: a case study of carabids in an alluvial forest. Ecography 24: 470-482.

Butterfield J., Luff M.L., Baines M. \& Eyre M.D. 1995: Carabid beetle communities as indicators of conservation potential in upland forests. Forest Ecol. Manag. 79: 63-77.

Currie C.R., Spence J.R. \& Niemelä J. 1996: Competition, cannibalism and intraguild predation among ground beetles (Coleoptera: Carabidae): a laboratory study. Coleopt. Bull. 50: 135-148.

Gardner S.M., Cabido M.R., Valladares G.R. \& Diaz S. 1995: The influence of habitat structure on arthropod diversity in Argentine semi-arid Chaco forest. J. Veg. Sci. 6: 349-356.

Gotelli N.J. \& Graves G.R. 1996: Null Models in Ecology. Smithsonian Institution Press, Washington DC, 368 pp.

Gotelli N.J. \& Colwell R.K. 2001: Quantifying biodiversity: procedures and pitfalls in the measurement and comparison of species richness. Ecol. Lett. 4: 379-391.

Gotelli N.J. \& Entsminger G.L. 2010: EcoSim: Null Models Software for Ecology. Version 7. Acquired Intelligence Inc. \& Kesey-Bear. Jericho, VT 05465. [WWW document]. URL $\mathrm{http}: / /$ garyentsminger.com/ecosim.htm [accessed 2010].

GunNarsson B., NitTérus K. \& Wirdenäs P. 2004: Effects of logging residue removal on ground-active beetles in temperate forests. Forest Ecol. Manag. 201: 229-239.

Halme E. \& Niemelä J. 1993: Carabid beetles in fragments of coniferous forest. Ann. Zool. Fenn. 30: 17-30.

Huk T. 2009: Carabid beetle (Coleoptera: Carabidae) communities - shaped by interspecific competition? Braunschw. Naturkd. Schr. 8: 439-447. 
Ings T.C. \& HartLEy S.E. 1999: The effect of habitat structure on carabid communities during the regeneration of a native Scottish forest. Forest Ecol. Manag. 119: 123-136.

Jukes M.R., Peace A.J. \& Ferris R. 2001: Carabid beetle communities associated with coniferous plantations in Britain: the influence of site, ground vegetation and stand structure. Forest Ecol. Manag. 148: 271-286.

Koivula M., KuKKonen J. \& Niemelä J. 2002: Boreal carabidbeetle (Coleoptera, Carabidae) assemblages along the clear-cut originated succession gradient. Biodivers. Conserv. 11: $1269-1288$.

LoReAu M. 1990: Competition in a carabids beetle community: a field experiment. Oikos 58: 25-38.

Lortie C.J., Brooker R.W., Choler P., Kikvidze Z., Michalet R., Pugnaire F.I. \& Callaway R.M. 2004: Rethinking plant community theory. Oikos 107: 433-438.

Magura T. 2002: Carabids and forest edge: spatial pattern and edge effect. Forest Ecol. Manag. 157: 23-37.

MagurRan A.E. 2004: Measuring Biological Diversity. Blackwell, Oxford, $256 \mathrm{pp}$.

Mazía C.N., Chaneton E.J. \& Kitzberger T. 2006: Small-scale habitat use and assemblage structure of ground-dwelling beetles in a Patagonian shrub steppe. J. Arid Environ. 67: 177-194.

Melis C., Olsen C.B., Hyllvang M., Gobbi M., Stokke B.G. \& RøskAFt E. 2010: The effect of traffic intensity on ground beetle (Coleoptera: Carabidae) aseemblages in central Sweden. J. Insect Conserv. 14: 159-168.

Migliorini M., Petrioli A. \& Bernini F. 2002: Comparative analysis of two edaphic zoocoenoses (oribatid mites and carabid beetles) in five habitats of the "Pietraporciana" and "Lucciolabella" nature reserves (Orcia valley, central Italy). Acta Oecol. 23: 361-374.

Mullen K., O’Halloran J., Breen J., Giller P., Pithon J. \& Kelly T. 2008: Distribution and composition of carabid beetle (Coleoptera, Carabidae) communities across the plantation forest cycle-implications for management. Forest Ecol. Manag. 256: 624-632.

NieMELÄ J. 1993: Interspecific competition in ground-beetle assemblages (Carabidae): what have we learned? Oikos 66: $325-335$.

Niemelä J. \& Kotze D.J. 2009: Carabid beetle assemblages along urban to rural gradients: A review. Landsc. Urban Plan. 92: $65-71$.

Niemelä J. \& Spence J.R. 1994: Distribution of forest dwelling carabids (Coleoptera): spatial scale and the concept of communities. Ecography 17: 166-175.

Niemelä J., Haila Y. \& Punttila P. 1996: The importance of small-scale heterogeneity in boreal forests: variation in diver- sity of forest-floor invertebrates across the succession gradient. Ecography 19: 352-368.

Niemelä J., Kotze J., Ashworth A., Brandmayr P., Desender K., New T., Penev L., Samways M. \& Spence J. 2000: The search for common anthropogenic impacts on biodiversity: a global network. J. Insect Conserv. 4: 3-9.

OKUZAKi Y., TаKami Y. \& Sota T. 2010: Resource partitioning or reproductive isolation: the ecological role of body size differences among closely related species in sympatry. J. Anim. Ecol. 79: 383-392.

Pearce J.L. \& Venier L.A. 2006: The use of ground beetles (Coleoptera: Carabidae) and spiders (Araneae) as bioindicators of sustainable forest management: A review. Ecol. Indic. 6: 780-793.

Poole A., Gormally M. \& Skeffington M.S. 2003: The flora and carabid beetle fauna of a mature and regenerating seminatural oak woodland in south-east Ireland. Forest Ecol. Manag. 177: 207-220.

Rainio J. \& NIEMElä J. 2003: Ground beetles (Coleoptera: Carabidae) as bioindicators. Biodivers. Conserv. 12: 487-506.

Rodríguez-Gironés M.A. \& SAntamaría L. 2006: A new algorithm to calculate the nestedness temperature of presenceabsence matrices. J. Biogeogr. 33: 924-935.

Sackmann P., Ruggiero A., Kun M. \& Farji-Brener A.G. 2006: Efficiency of a rapid assessment of the diversity of ground beetles and ants, in natural and disturbed habitats of the Nahuel Huapi region (NW Patagonia, Argentina). Biodivers. Conserv. 15: 2061-2084.

SCott W.A. \& Anderson R. 2003: Temporal and spatial variation in carabid assemblages from the United Kindom Environmental Change Network. Biol. Conserv. 110: 197-210.

Sota T., Takami Y., Kubota K., UjiIE M. \& IshiKawa R. 2000: Interspecific body size differentiation in species assemblages of the carabid subgenus Ohomopterus in Japan. Popul. Ecol. 42: 279-291.

Ter Braak C.J.F. \& Šmilauer P. 2002: CANOCO Reference Manual and CanoDraw for Windows User's Guide: Software for Canonical Community Ordination (version 4.5). Microcomputer Power, Ithaca, N.Y., 500 pp.

Thiele H.U. 1977: Carabid Beetles in Their Environments. A Study on Habitat Selection by Adaptations in Physiology and Behaviour. Springer, Berlin, 369 pp.

YoKohari M. \& KURITA H. 2003: Mechanisms of Saitama landscape transformation. In Takeuchi K., Brown R.D., Washitani I., Tsunekawa A. \& Yokohari M. (eds): Satoyama. The Traditional Rural Landscape of Japan. Springer, Berlin, pp. 71-80.

Received December 19, 2010; revised and accepted February 14, 2011 